\title{
Safety analysis of Novat tailings dam
}

\author{
Florian $\mathrm{Tatu}^{1, *}$ and Dan Stematiu ${ }^{1}$ \\ ${ }^{1}$ Department of Hydrotechnical Structures, Technical University of Civil Engineering Bucharest, Romania
}

\begin{abstract}
The Novat tailings dam is located in the upper basin of the Novat stream, which flows through the Ursul stream into the Vaser River. Mention should be made that the basins of the Vaser River and Viseu are protected areas, which do not allow any discharges downstream and require the repumping of the cleared waters back to the flotation of Baia Borsa mine. Overtopping of the main and downstream dams, with their partial destruction, occurred on 10 March 2000 as a result of the torrential rains falling across the entire surface of the Novat stream receiving basin. Before the accident occurred, deposits from the tailings dam reached $802.0 \mathrm{maSL}$, with the clear water mirror at 804.50 maSL. The paper deals with the safety of Novat tailings dam after the accident in March 2000.
\end{abstract}

\section{Introduction}

Tailings dams are special retention hydraulic engineering structures, designed to safely store tailings from the mine processing plant and discharge the inflows coming in the site. They have many elements in common with water storage dams, but the nature of the retained materials as well as the way of in stage construction and operation differentiates them [1-2].

In terms of engineering practice, safety is "the hope that a construction behaves according to expectation", respectively, not to fail (break) under the action of the loads, within a given timeframe (generally the projected lifetime) [3]

Release of a tailings and uncontrolled release of barred waste can have serious consequences for public safety (population), the environment and the holder or operator. Failures of tailings dams continue to appear in spite of the improved technologies available for design, construction and operation. The consequences of these failures were large economic losses, environmental degradation and, in many cases, loss of human lives [1].

The purpose of this paper is to analyze the safety of the Novat tailings dam, based on the technical accident that occurred on March 2000.

\section{Site description}

Novat tailings dam is located in the upper basin of the Novat stream (figure 1). The site is located on the administrative territory of Viseu de Sus, Maramures County.

It was built between 1983 and 1994 (the year in which it was put into operation).
The pond was designed to store tailings from a flotation plant located on another valley called Cisla, which is a tributary of the Viseu River. Given the restrictions on water management, the pond was located on the Novat Rosu valley because there were already five ponds on the Cisla valley and there was no room for another pond. The construction of the pond started with the creation of an embankment dam on the Novat valley, up to the height of $26 \mathrm{~m}$.

Novat TDF was designed without the possibility of downstream water discharge due to the fact that the valley of Vaser, a tributary of the Novat stream, is a protected area.

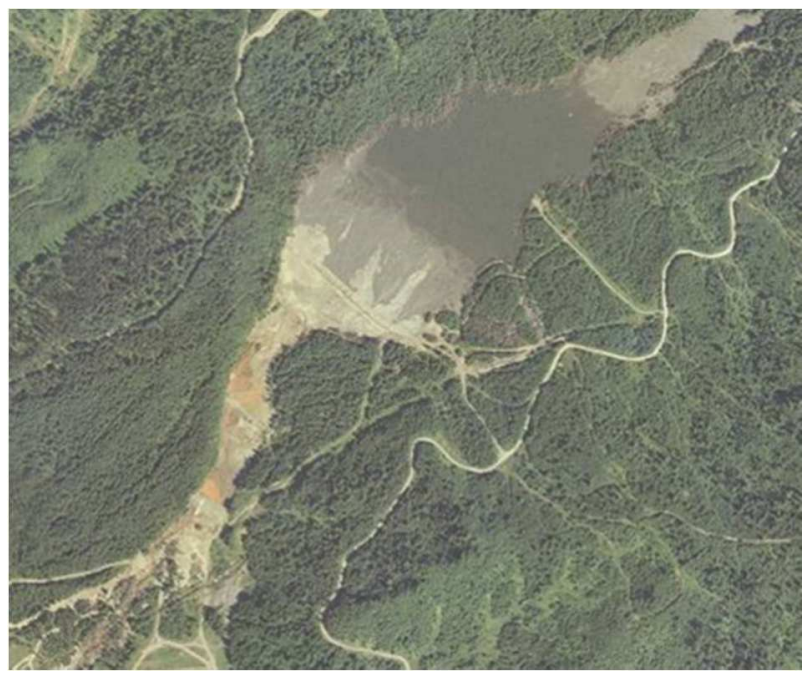

Fig. 1. Satellite view of Novat tailings dam.

* Corresponding author: floriantatu@gmail.com 
The following elements are included in the Novat development (figure 2):

- The main embankment, made from rockfill, $26 \mathrm{~m}$ high, with the crest level at 800 maSL and slopes 1: 2 upstream and 1:3 downstream.

- The downstream toe embankment, located about $260 \mathrm{~m}$ downstream of the tailings dam, with the crest level at 775 maSL.

- The seepage dam, located about $154 \mathrm{~m}$ downstream of the downstream toe embankment, has the crest level at 767 maSL. The dam aims to accumulate the seepage from the tailings dam and drive it to the infiltrated water pumping station, downstream, through which it is led back into the tailings dam.

- The upstream toe embankment (diversion dam), located about $1000 \mathrm{~m}$ from the dam of the tailings pond, is located at about $827 \mathrm{maSL}$. The dam aims at delimiting the flows of the Novat stream outside the tailings pond area and channeling them through the derivation gallery.

- The hydrotechnic derivation gallery (diversion tunnel) of the Novat stream, about $1405 \mathrm{~m}$ in length, is located on the left side of the tailings pond. It has a diameter of about $3.0 \mathrm{~m}$ and a maximum transport capacity estimated at $90 \mathrm{~m}^{3} / \mathrm{s}$. Deviated flows through the gallery are downloaded into the Novat stream, downstream of the seepage dam.

- The tailings transport system at the tailings pond is through a $400 \mathrm{~mm}$ diameter metal pipe. The tailings distribution is made through a $150 \mathrm{~mm}$ diameter service pipe system perpendicular to the crest of initial dam of the tailings dam.

- The clear water discharge system of the tailings dam is through a pumping station located to the tail of the tailings storage on its left slope.

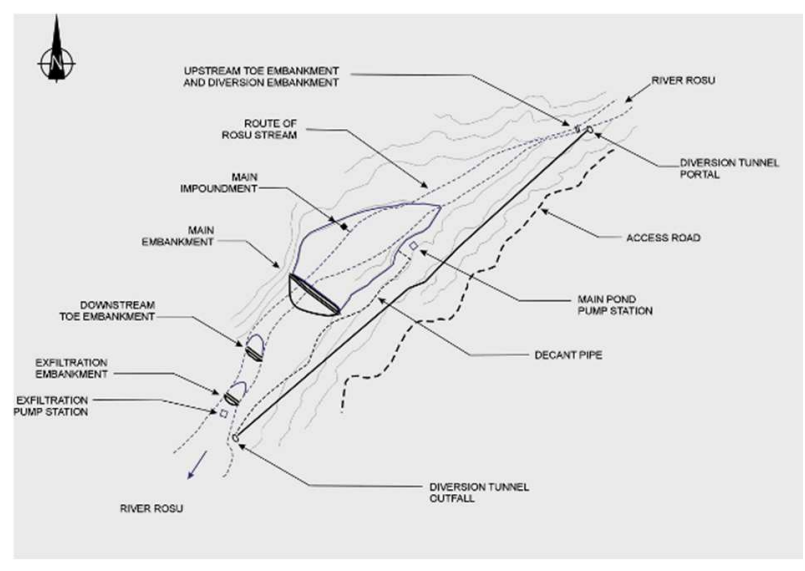

Fig. 2. Novat TDF.

Prior to the accident, deposits from the TMF reached $802.0 \mathrm{maSL}$, with the clear water mirror reading 804.50 maSL.

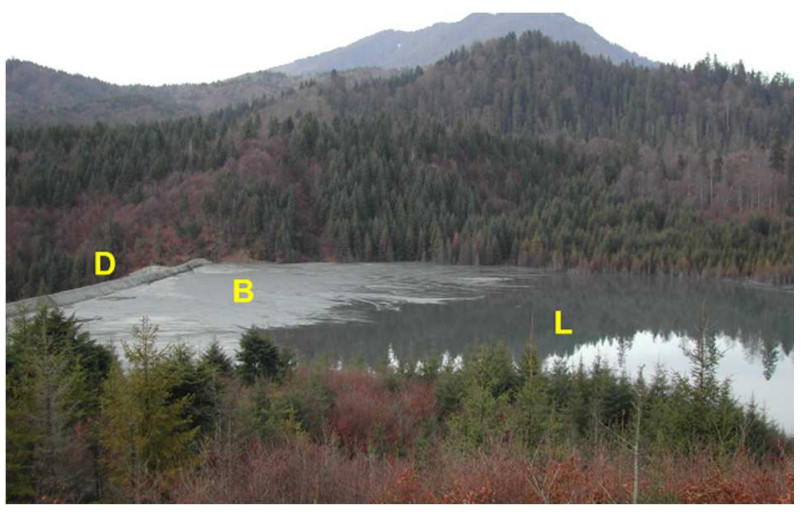

Fig. 3. Novat TDF, beach (B) embankment dam (D) and lagoon (L)

Mention should be made that prior to the technical accident, a siphoning was made with the intention of a better discharge of water from the pond [4-5].

\section{Technical accident description}

Overtopping of the main and downstream dams, with their partial destruction, occurred on 10 March 2000 as a result of the torrential rains falling across the entire surface of the Novat stream receiving basin.

The sequence of events preceding the technical accident was as follows:

From mid-December 1999 to the end of January 2000 in the Novat Basin precipitations fell in the form of snow over $120 \mathrm{~mm}$. Temperatures have fallen below $0^{\circ} \mathrm{C}$ since December 21 and stabilized at $-10^{\circ} \mathrm{C}$ from December 22 to January 27 when they climbed sharply to $8^{\circ} \mathrm{C}$.

During 8 to 10 March, torrential rains that led to snow melting occurred, the level of water in the pond increased very quickly and on 9 March 2000, 22:10 hours flooded the pumping station that ensured discharge of the pond waters. As a result, the pumps have been turned off to avoid short circuiting. Later on, a pumping but lowcapacity floating station was installed.

On 10 March, at 11:00, the main dam was overtopped and a $25 \mathrm{~m}$ wide and $10 \mathrm{~m}$ deep breach formed the right slope. The breach subsequently expanded until the leakage out of the pond was stopped by a coferdam made of tailings and fir branches. On 13 March, any waste water evacuation in the Novat stream was completely stopped. The main damage caused by the accident in March 2000 was materialized by:

- the partial destruction by overtopping of the main dam with the area adjacent to the right slope over a length of about $50 \mathrm{~m}$ and $20 \mathrm{~m}$ deep.

- destruction by overtopping of the downstream toe dam over a width of about $50 \mathrm{~m}$, in the area of the right slope connection and practically full clogging of the volume created by this dam.

- destruction by overtopping of the seepage collection dam on a side of about $45 \mathrm{~m}$, also in the right bank connection area; the discharge also produced the destruction of the existing concrete diaphragm in the dam body to prevent infiltration. 
Around 100,000 cubic meters of water and about 20,000 tons of tailings containing heavy metals passed through the main dam breach. Part of the material was retained by the two downstream dams, and the rest flowed to Novat river, from Novat to Vaser river, then to Viseu and finally to Tisa river.

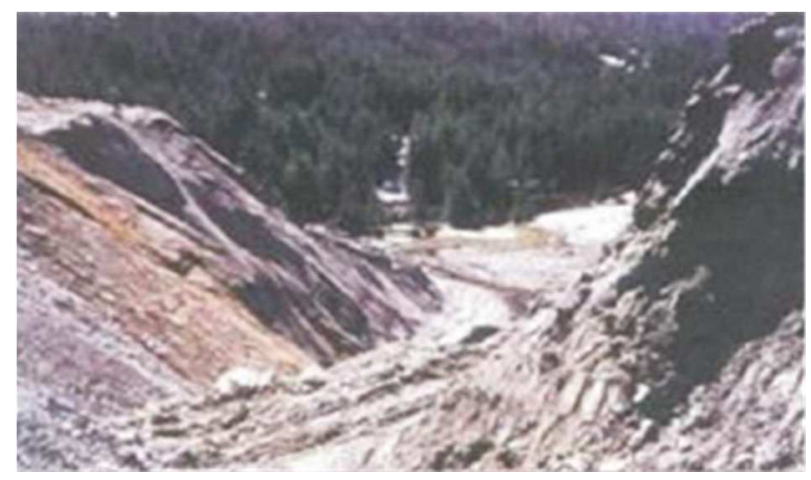

Fig. 4. Breach - upstream view

The main cause of the technical accident was the closed circuit operating system. The area downstream of the pond is a protected area so that any discharge of downstream pond is prohibited. As a result, the Novat pond did not have a safety deck capable of evacuating the water surplus that would have entered the pond due to excessive precipitation on the surface of the pond and its slopes or the upstream basin. The waters decanted into the pond were recirculated to the processing plant.

Excessive precipitation was coincident with the melting of snow on the surface of the pond, and the tributary flows exceeded the hydraulic capacity of the derivation gallery. Rapid raising of the water in the pond due the upstream inflow has shut down the water pumping station and discharge towards the plant was stopped, so that the overtopping of the dam occured.

A secondary cause was the lack of guards specified in the operating rules. The pond was designed for a capacity of 2 million cubic meters but the deposition rate was lower so that only $400,000 \mathrm{~m}^{3}$ of tailings was deposited. The material available for raisings was less than anticipated, and the crest level was lower than that of the specifications.

After the accident, repair works on the destroyed or damaged facilities were conducted as a matter of urgency, to restore the tailings dam functionality [4].

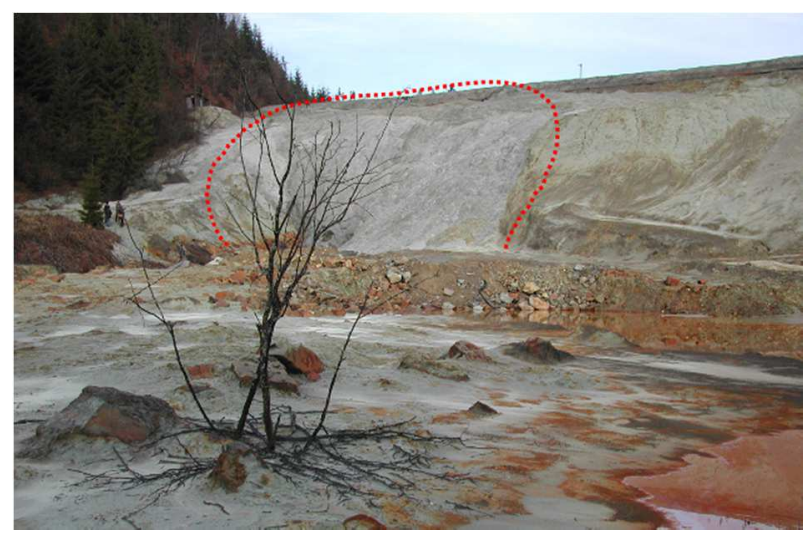

Fig. 5. Novat TDF - area of breach from March 2000

\section{Safety analysis of Novat tailings dam}

The stability analysis was done with GeoStudio 2018 program, a software product of GEO-SLOPE International Ltd.

The first step modeling was made in the SEEP/W module for the evaluation of the depression curve, and then the stability analysis in the SLOPE/W module [6-11].

The model of Novat TMF created in the GeoStudio 2018 program is shown in figure 6 .

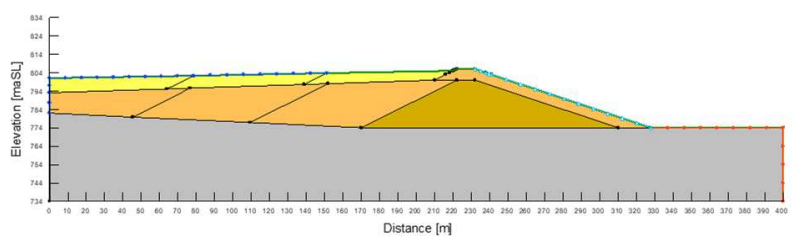

Fig. 6. Novat TDF model

In SEEP/W modeling, the permeability of materials and the characteristic elevations that were taken into account are presented in Tables 1 and 2.

The characteristic geotechnical parameters that were used in the SLOPE/W model are presented in Tabel 3 [10].

Table 1. Permeability of materials.

\begin{tabular}{|l|l|}
\hline \multirow{4}{*}{ Material } & \multicolumn{1}{c}{\begin{tabular}{c}
\multicolumn{1}{c}{$\begin{array}{c}\text { Permeability }-\mathrm{k} / \mathrm{s}) \\
\text { Tailings }\end{array}$} \\
\cline { 2 - 2 }
\end{tabular}} \\
\cline { 2 - 2 } Coarse $-2 \times 10^{-4}$ \\
\cline { 2 - 2 } Consolidated tailings & fine $-8.47 \times 10^{-7}$ \\
\cline { 2 - 2 } & average $-5 \times 10^{-5}$ \\
\cline { 2 - 2 } & fine $-1.2 \times 10^{-6}$ \\
\hline Bedrock & $1 \times 10^{-18}$ \\
\hline Gravel & $9 \times 10^{-4}$ \\
\hline Siphoning & $1.5 \times 10^{-2}$ \\
\hline
\end{tabular}

Table 2. Characteristic levels.

\begin{tabular}{|c|c|c|}
\hline 1 & Base of the dam level & $774.00 \mathrm{maSL}$ \\
\hline 2 & Crest level of starter dam & $800.00 \mathrm{maSL}$ \\
\hline 3 & Crest level of dyke rises & $806.00 \mathrm{maSL}$ \\
\hline 4 & $\begin{array}{c}\text { Tailings level at upstream } \\
\text { slope }\end{array}$ & $805.00 \mathrm{maSL}$ \\
\hline 5 & Water mirror level & $803.50-805.50 \mathrm{maSL}$ \\
\hline
\end{tabular}


Table 3. Characteristic geotechnical parameters.

\begin{tabular}{|l|c|c|c|}
\hline \multicolumn{1}{|c|}{ Material } & $\begin{array}{c}\gamma \\
\left(\mathrm{kN} / \mathrm{m}^{3}\right)\end{array}$ & $\begin{array}{c}\mathrm{c} \\
(\mathrm{kPa})\end{array}$ & $\begin{array}{c}\varnothing \\
\left({ }^{\circ}\right)\end{array}$ \\
\hline Tailings & 18 & 0 & 33 \\
\hline $\begin{array}{l}\text { Consolidated } \\
\text { tailings }\end{array}$ & 18 & 5 & 35 \\
\hline Bedrock & \multicolumn{3}{|c|}{ Impenetrable } \\
\hline Gravel & 20 & 0 & 40 \\
\hline Siphoning & 18 & 0 & 30 \\
\hline
\end{tabular}

The critical hydraulic gradient was evaluated based on the relationship 1 and resulted as being 0.54 .

$$
i_{c r}=\frac{(1-n) \cdot\left(\gamma_{s}-\gamma_{w}\right)}{\gamma_{w}}
$$

with the values of parameters:

$n=0.33 ; \gamma_{s}=18 \mathrm{kN} / \mathrm{m}^{3}$ and $\gamma_{w}=10 \mathrm{kN} / \mathrm{m}^{3}$

The Morgenstern-Price limit equlibrium method was used for the stability analysis in SLOPE/W model defining the circular slip surfaces by Grid and Radius method.

In the first phase, the model was analysed considering the level of water mirror at $803.50 \mathrm{maSL}$, which corresponds to a beach of approximately $80 \mathrm{~m}$. The following results were obtained from the analyzes:

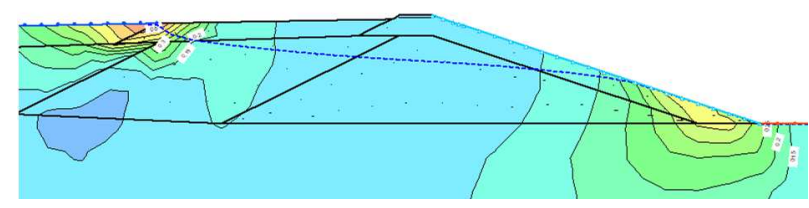

Fig. 7. Hydraulic Gradients, water level at $803.50 \mathrm{maSL}$

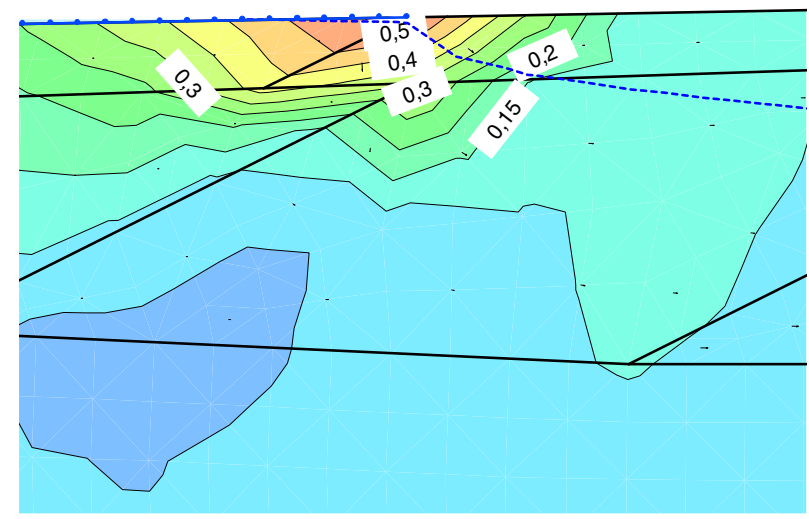

Fig. 8. Upstream Hydraulic Gradients

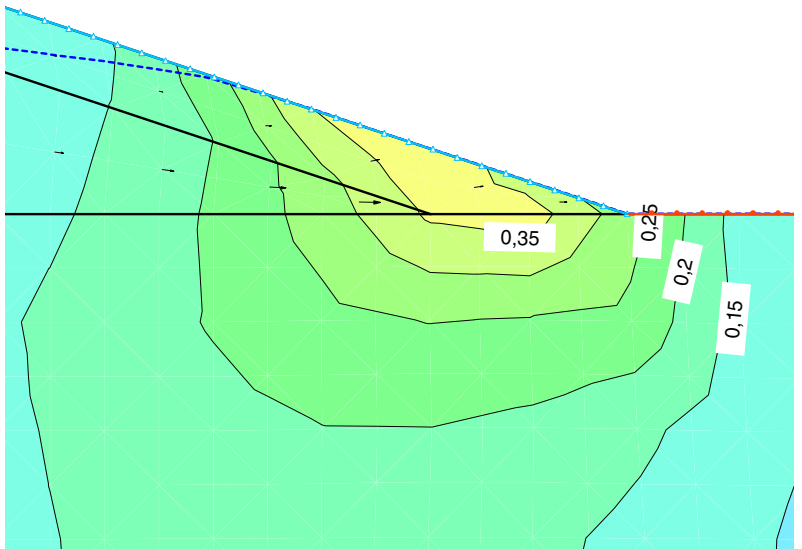

Fig. 9. Downstream Hydraulic Gradients

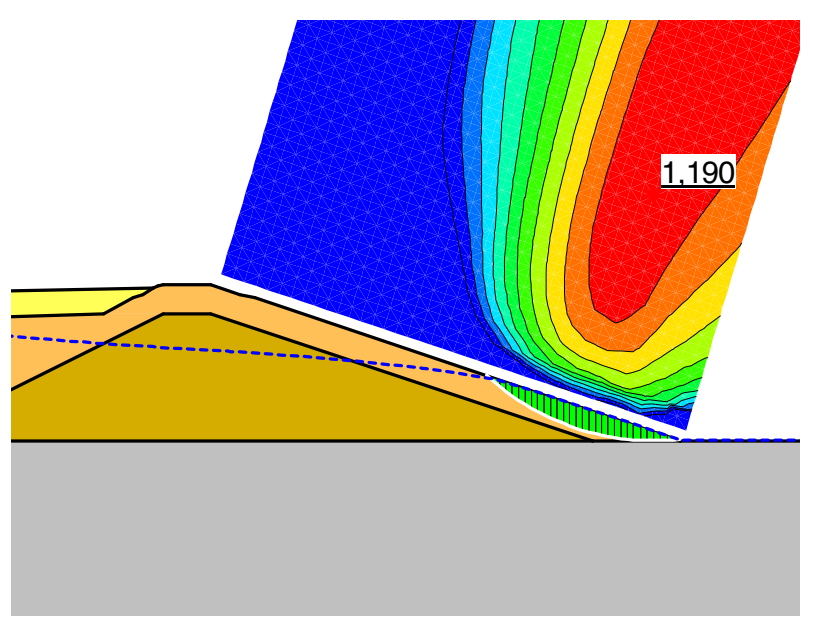

Fig. 10. Safety factor (FOS), water level at $803.50 \mathrm{maSL}$

It can be seen that the maximum hydraulic gradients are below the value of the critical hydraulic gradient, not leading to hydrodynamic erosion of the tailings.

The safety factor obtained is greater than 1 , which means that there are no problems under these conditions.

Later, the model was analyzed considering the level of water mirror at $805.50 \mathrm{maSL}$, the water being in contact with the upstream slope and $0.50 \mathrm{~m}$ below the crest.

Two hypotheses were analyzed: first one in which the structure of the pond is unchanged and the second one corresponding to the effect of siphoning (that creats a zone with a material having weaker geomechanical properties). After the analyzes, the following results were obtained:

\section{Hypothesis 1 (unchanged structure)}

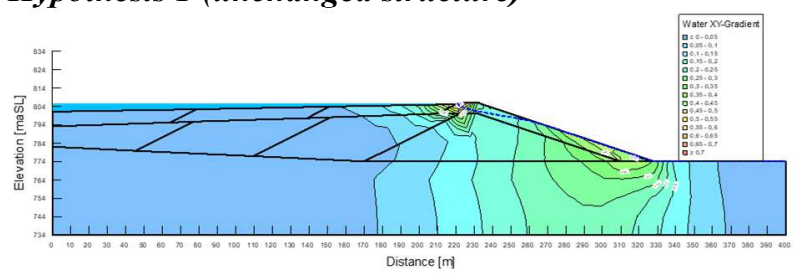

Fig. 11. Hydraulic Gradients, water level at $805.50 \mathrm{maSL}$ 


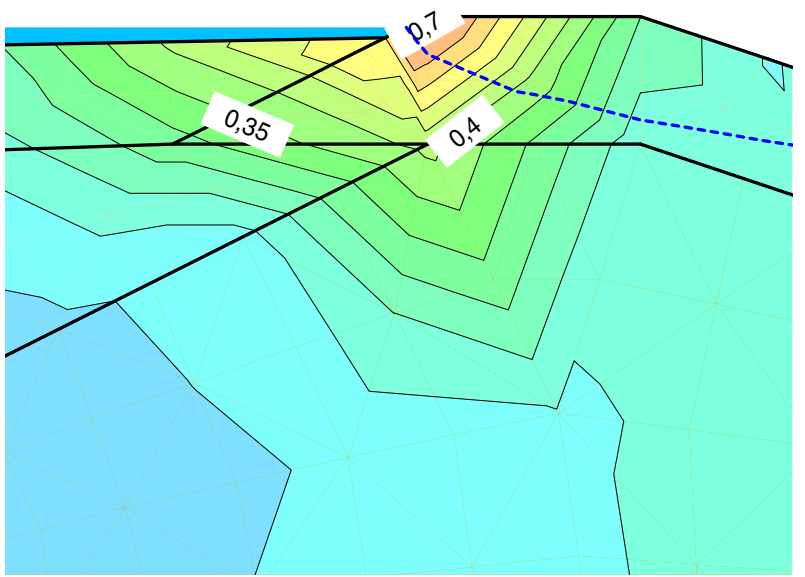

Fig. 12. Upstream Hydraulic Gradients

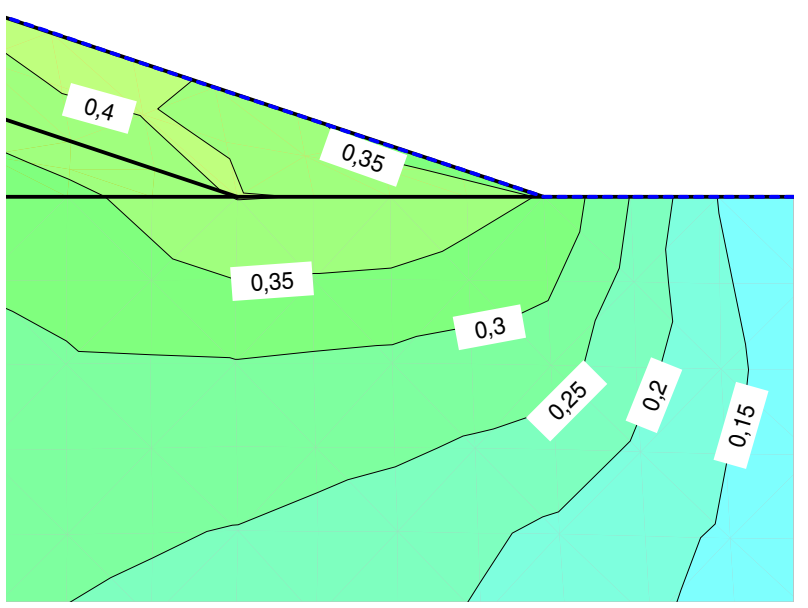

Fig. 13. Downstream Hydraulic Gradients

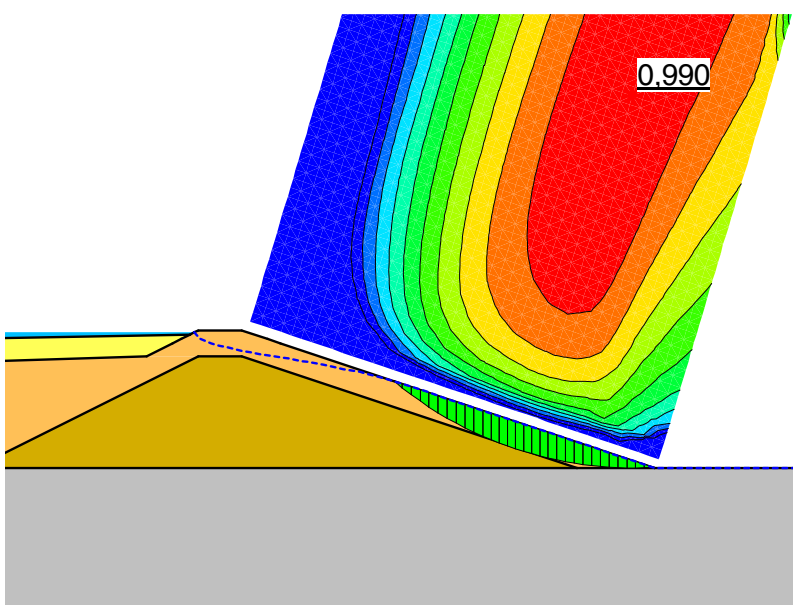

Fig. 14. Safety factor (FOS), water level at $805.50 \mathrm{maSL}$

It can be seen that the maximum hydraulic gradients are above the value of the critical hydraulic gradient, leading to hydrodynamic entrainment of the tailings.

The safety factor obtained is below 1 , which means that in these conditions there are problems with the stability and safety of the tailings dam.

\section{Hypothesis 2 (with siphoning)}

The siphoning area (weaker material) was introduced into the model at $2 \mathrm{~m}$ under the crest and with a layer of $1 \mathrm{~m}$ thick.

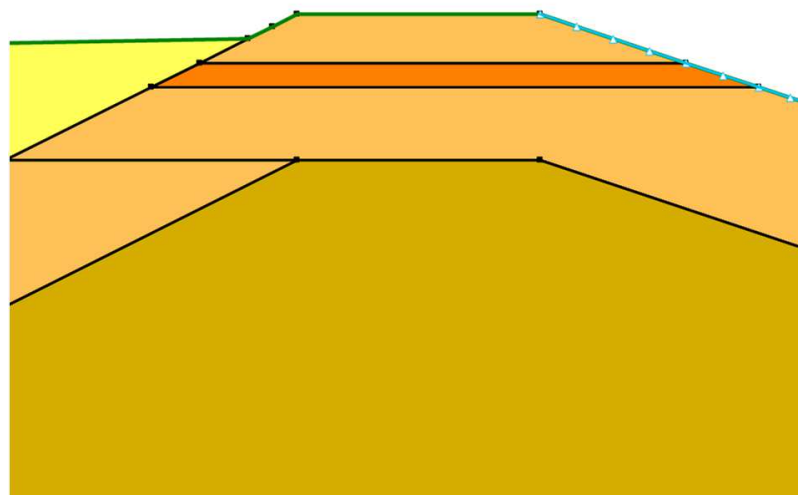

Fig. 15. Siphoning zone in the model

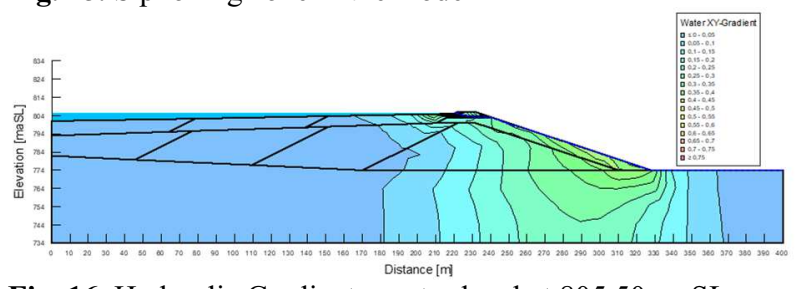

Fig. 16. Hydraulic Gradients, water level at $805.50 \mathrm{maSL}$

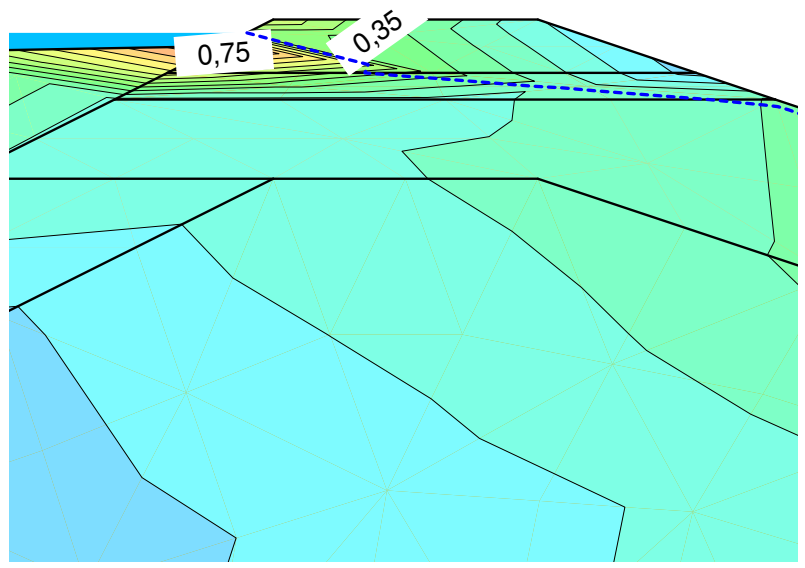

Fig. 17. Upstream Hydraulic Gradients

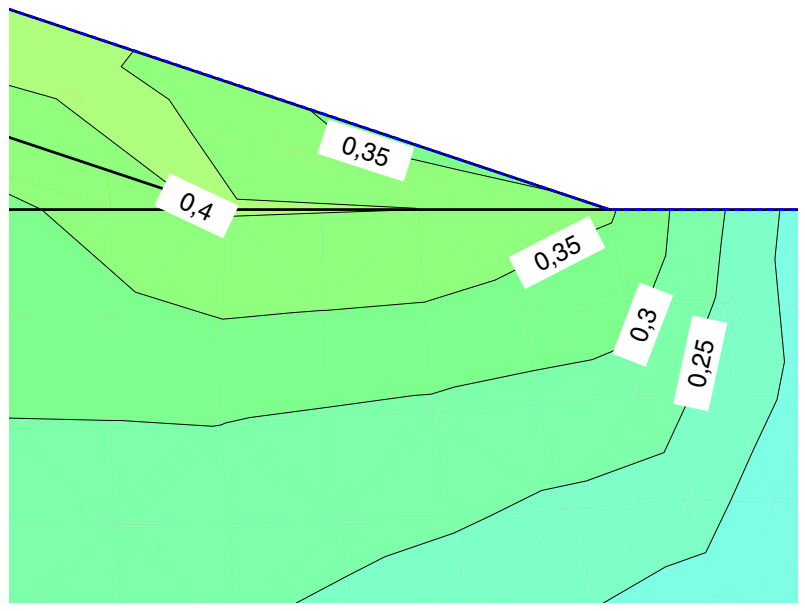

Fig. 18. Downstream Hydraulic Gradients 


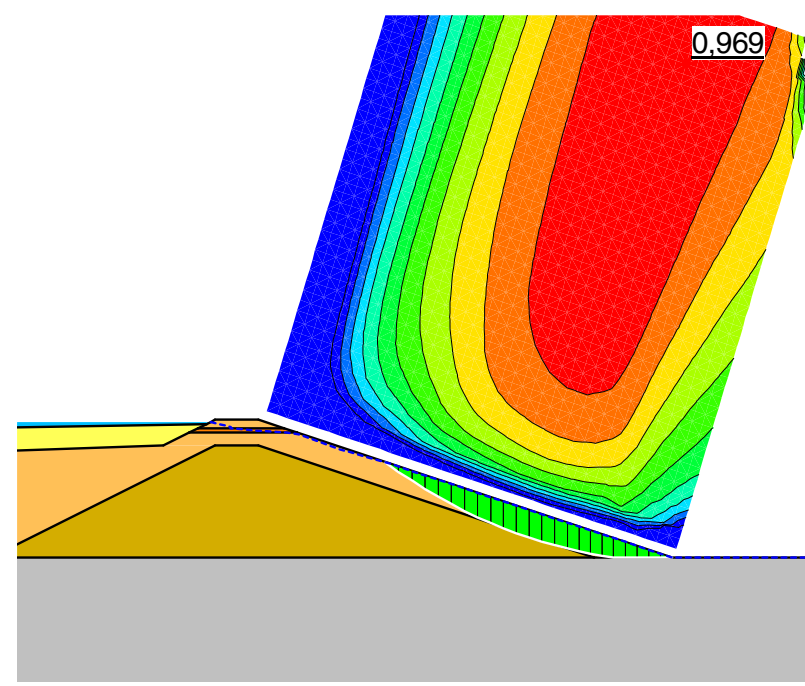

Fig. 19. Safety factor (FOS), water level at $805.50 \mathrm{maSL}$

It can be seen that the maximum hydraulic gradients are above the value of the critical hydraulic gradient, leading to hydrodynamic internal erosion of the tailings.

The safety factor obtained is below 1 , which means that in these conditions there are problems with stability and safety of the tailings dam [5].

\section{Conclusions}

Under normal operation conditions the safety of Novat tailings was in the frame of safety regulations.

The unexpected rise of water table in the pond was the main cause of the dam failure. The pumping station was flooded, the dam was overtopped and a breach was created by external erosion. The changes of the safety conditions induced by the pond level recorded during the failure triggering were modeled by means of a finite element approach. The modeling results have shown that in both hypotheses, the hydraulic gradients at dam crest are higher than the critical hydraulic one (0.54), thus explaining the internal erosion that started the dam failure. The reduced safety factor reviled by stability analysis is just a consequence. The siphoning initiated by pond operator in order to control the water level was not a benefic measure, the hydraulic gradients being even higher than the ones without siphoning ( 0.75 as compared to 0.7 ) due to the weaker material and higher hydraulic permeability in the siphoning area.

The results corresponding to hypothesis 2 are mostly qualitative, since in mathematical modeling it is very difficult to reproduce the siphoning area, both in terms of modeling of the structure itself and of the exact geotechnical parameters.

\section{References}

1. ICOLD Committee on Mine and Industrial Tailings Dams. Bulletin 121. Tailings dams. Risk of dangerous occurrences. Lessons learnt from practical experiences. Paris (2001)
2. Vick, Steven.G. Planning, design and analysis of tailings dams. BiTech Publishers Ltd. Richmond, B.C (1990)

3. Stematiu, D.; Ionescu, S.; Abdulamit, A. Dams safety and risk management. Conspress Publishing House, Bucharest (2010) (in Romanian)

4. Stematiu, D. Accidents and incidents occurred at hydraulic structures. Reports from my experience. AGIR Publishing House, Bucharest (2018) (in Romanian)

5. Tatu, F. Approaches in evaluation the probability of failure. Research report number 2 (2017) (in Romanian)

6. GEOSLOPE International Ltd. 2017. Heat and mass transfer modeling with GeoStudio 2018 (Second Edition). Calgary, Alberta, Canada

7. GEOSLOPE International Ltd. 2017. Stability modeling with GeoStudio 2018. Calgary, Alberta, Canada

8. Fell, R. et al. Geotechnical Engineering of Dams, 2nd edition. CRC Press Taylor \& Francis Group, London, UK (2014)

9. Independent Expert Engineering Investigation and Review Panel, Report on Mount Polley Tailings Storage Facility Breach (2015)

10. Norbert R. Morgenstern, Steven G. Vick et. al. Fundao Tailings Dam Review Panel, Report on the Immediate Causes of the Failure of the Fundao Dam (2016)

11. Vanden Berghe, J.-F., Ballard, J.-C., Wintgens, J.-F. and List, B. 2011, Geotechnical Risks Related to Tailings Dam Operations - Proceedings Tailings and Mine Waste, Vancouver, BC (2011). 